\title{
A Modelagem Matemática na educação como recurso na formação crítica dos alunos no Ensino Fundamental
}

\author{
André Luiz Rocha \\ Marcia Maria Fusaro Pinto
}

\begin{abstract}
Resumo: Esse artigo traz resultados de pesquisa sobre possibilidades e limites de intervenção utilizando modelagem matemática em uma vertente crítica. $O$ foco são as reflexões matemáticas que emergem em ambiente de modelagem constituído como um cenário para investigação, considerando as contribuições para uma formação crítica dos participantes. Referenciais em Skovsmose $(2000,2001,2008)$ e a metodologia em Skovsmose e Borba (2004) sustentam seu desenvolvimento. Participantes são o primeiro autor do artigo e seis alunos voluntários de uma escola pública. Resultados evidenciam que as atividades de modelagem realizadas surgem como desencadeadoras de reflexões sobre a Matemática e seu uso, ampliando visão inicial que identifica aquele conhecimento com o que é ensinado na escola e o reduz às quatro operações em seu uso cotidiano, enquanto contribuem para a formação crítica dos estudantes.
\end{abstract}

Palavras-chave: Modelagem Matemática. Educação Matemática Crítica. Cenários para Investigação.

\section{Mathematical Modeling in education as a resource in the students' critical education at school}

\begin{abstract}
This article presents results from research on possibilities and limits of an intervention at school using mathematical modeling from a critical perspective as a resource for teaching. The focus is on mathematical reflections emerging in a modeling scenario constituted as landscape for investigation, accounting for contributions to critical education of participants. Skovsmose $(2000,2001,2008)$ and the methodology in Skovsmose and Borba (2004) are references for the project development. Participants are the first author and six students from a public school. Results show that the modeling activities emerge as triggers for reflections on mathematics and its use, expanding students' initial views identifying mathematical knowledge with the Mathematics taught at school and reducing it to the four operations in its daily use, while contributing to critical mathematical education of the students.
\end{abstract}

Keywords: Mathematical Modeling. Critical Mathematics Education. Landscapes of Investigation.

\section{Modelación Matemática en la educación como recurso en la}

André Luiz Rocha

Mestre em Ensino de Matemática.

Professor da Secretaria Municipal de

Educação do Rio de Janeiro. Rio de Janeiro, Brasil.

iD https://orcid.org/0000-0001-8959-4316 $\triangle$ andrerocha@live.dk

Marcia Maria Fusaro Pinto Doutora em Educação Matemática.

Professora do Programa de PósGraduação em Ensino de Matemática da Universidade Federal do Rio de Janeiro (UFRJ). Rio de Janeiro, Brasil.

http://orcid.org/0000-0001-5308-0487 $\bowtie$ marciafusaro@gmail.com

Recebido em 06/11/2019 Aceito em 20/04/2020 Publicado em 22/04/2020 \section{formación crítica de estudiantes en la escola}

Resumen: Este artículo ofrece resultados de investigación sobre las posibilidades y límites de intervención utilizando modelación matemática en perspectiva crítica. El enfoque son reflexiones matemáticas que surgen entorno de modelación constituido como Paisajes de Investigación, considerando las contribuciones a formación crítica de los participantes. Las referencias de Skovsmose $(2000,2001,2008)$ y la metodología en Skovsmose y Borba (2004) apoyan su desarrollo. Los participantes son el primer autor y seis estudiantes voluntarios de una escuela pública. Los resultados muestran que las actividades de modelación realizadas emergen como disparador para las reflexiones sobre Matemáticas y su uso, ampliando la visión inicial que identifica ese conocimiento con su enseñanza en la escuela lo reduciendo a las cuatro operaciones en su uso diario, al tiempo que contribuye a la capacitación crítica y política estudiantil.

Palabras clave: Modelacion Matematica. Educación Matemática Crítica. Paisajes de Investigación. 


\section{Introdução}

O histórico de nossas experiências como alunos e professores e o interesse por investigar alternativas para ensinar Matemática, problematizando-a, resultaram na proposição de uma experiência com a Modelagem Matemática como um modo de reconstruir nossa prática em sala de aula.

Como ainda é muito comum no ensino da Matemática nas escolas, apesar dos esforços de educadores, pesquisadores e políticas públicas por meio das orientações do Ministério da Educação, o conhecimento é apresentado aos estudantes de forma desconexa do seu cotidiano e sem relações claras com a Educação em outras ciências.

Tal abordagem, que nos parece dominante para apresentação do conhecimento matemático, remete a perspectivas conhecidas como tradicionais. Fiorentini (1995) as caracteriza "pela sistematização lógica do conhecimento matemático a partir de elementos primitivos e de uma visão estática da matemática como se fosse a-histórica e dogmática" (p. 6). Subjacente a tais perspectivas parece haver a crença de que, para aprender Matemática, deve-se repetir deliberadamente uma coleção extensa de exercícios, que em geral são valorizados por seu resultado final e não pelo processo desenvolvido (SKOVSMOSE, 2008).

O resultado de tal ensino reduz-se por vezes à reprodução, muitas vezes mecânica, do conhecimento ensinado. Skovsmose (2008) considera que ambientes como esse estão inseridos em paradigma que ele denomina de Paradigma do Exercício. Nele parte-se da premissa de que, para aprender Matemática, os alunos deverão repetir técnicas e métodos sem problematizar ou levar em consideração a relevância de determinados conteúdos. Todos os dados do exercício e seu enunciado são aceitos sem questionamento, assumindo que todas as informações enunciadas são suficientes para sua resolução, que admite uma e somente uma resposta correta.

Assim como em Skovsmose (2008), abordagens em sala de aula como a descrita anteriormente também são problematizadas em Ponte e Quaresma (2016). Esses autores destacam que, em ambientes como os descritos acima, o exercício em Matemática é visto como um mecanismo para saber se aluno aprendeu a reproduzir o método, não tendo ele nenhum significado ou intenção de fazer com que 0 aluno reflita sobre o que está estudando. Ambos, Skovsmose (2008) e Ponte e Quaresma (2016) discutem investigação na aula de Matemática como uma alternativa pedagógica. Contudo, a proposta de Ponte e Quaresma (2016) é de que o estudante percorra o caminho de um matemático no processo investigativo, ressaltando a importância de apoiarmos a aprendizagem trazendo tarefas desafiadoras que permitam "que uma 
variedade de estratégias que possam ser comparadas e avaliadas, dando lugar a discussões interessantes (p. 52)". Skovsmose (2008), por sua vez, se preocupa com a formação do estudante reflexivo quando passa a questionar o papel da Matemática na sociedade.

Alternativas pedagógicas com tais características vêm sendo investigadas internacionalmente e em nosso país por educadores que pesquisam 0 uso da modelagem matemática na Educação Matemática. Araújo (2010) constrói um panorama da pesquisa em Modelagem na Educação Matemática no Brasil, organizando-o segundo três perspectivas: a origem histórica desse conhecimento no Brasil, ressaltando a relação com a comunidade internacional; a síntese de algumas pesquisas, discussões e publicações dedicadas à modelagem; e descrição e análise de pesquisas apresentadas em eventos científicos recentes. A intenção é caracterizar e compreender os interesses que movem esse campo. Araújo (2010) observa aspectos sobre a utilização de Modelagem Matemática na Educação no Brasil, a saber, uma forte defesa de que a modelagem é um caminho para atrair estudantes interessados, e consequentemente para promover a aprendizagem em Matemática, e a variedade de concepções sobre Modelagem Matemática. De sua análise, a Modelagem Matemática na educação depende do contexto educacional, dos profissionais envolvidos e do perfil dos estudantes, entre outros fatores. Uma de suas vertentes, a perspectiva sócio-critica, entende a Modelagem Matemática como uso de modelos matemáticos para resolver problemas reais.

A literatura de pesquisa traz resultados indicando que um ambiente de aprendizagem que decorre de atividades com modelagem pode facilitar a compreensão dos sistemas de conhecimento que se originaram a partir da realidade, em resultado a práticas desses grupos. $\mathrm{A}$ reflexão e a análise crítica sobre essa realidade podem auxiliar os alunos a entender as conexões entre a realidade e a formalização do conhecimento matemático decorrente dela. Neste sentido, D’Ambrósio (1990) ressalta a importância de reconhecer a base social do conhecimento matemático, envolvendo ideias, práticas e experiências matemáticas, sejam elas formais ou informais, inerentes a atividades cotidianas em grupos sociais distintos.

Ao levarmos em conta tais questões, inserimos nossa pesquisa na vertente sócio-crítica na Educação Matemática (BARBOSA, CALDEIRA e ARAÚJO, 2007; ARAÚJO, 2010). A Educação Matemática Crítica (EMC), adotada como uma referência teórica para desenvolvê-la, considera os desafios de um ensino de Matemática dando especial atenção aos aspectos políticos da educação. A EMC preocupa-se em revelar como a Matemática influencia os nossos ambientes culturais, tecnológicos e políticos, e os limites e possibilidades das funções que a competência matemática pode satisfazer. Isto significa iluminar os modos com que as técnicas matemáticas e 
modos de pensar podem operar ou operam em contextos sociais e políticos.

Assim a EMC não se dá por meio de um sistema, visto como tradicional, onde o professor é o único que possui voz. Alunos podem e devem participar do processo de aprendizagem, que possibilita aos que dele participam serem capazes de pensar e de relacionar os problemas apresentados em sala de aula com problemas do seu cotidiano. É em um contexto como esse que entendemos que essa pesquisa se justifica, já que queremos investigar e propor intervenções e projetos que conectem a Matemática a situações reais, contextualizadas, e significativas para os alunos, para que eles, como agentes, experimentem o conhecimento já adquirido de Matemática por meio de ambientes que possam se constituir como Cenários para Investigação. Com esta intenção, planejamos atividades de Modelagem Matemática buscando a constituição de cenários para investigação (SKOVSMOSE, 2000; SKOVSMOSE, 2008), como alternativa pedagógica ao Paradigma do Exercício¹.

Skovsmose (2008) discute seis ambientes de aprendizagem possíveis, baseados no Paradigma do Exercício e em Cenários para Investigação, com referências à Matemática Pura, à semi-realidade e à realidade (ver Quadro 1).

Quadro 1: Ambientes de Aprendizagem

\begin{tabular}{|c|c|c|}
\cline { 2 - 3 } \multicolumn{1}{c|}{} & Exercícios & $\begin{array}{c}\text { Cenários para } \\
\text { Investigação }\end{array}$ \\
\hline Referências à Matemática Pura & $(1)$ & $(2)$ \\
\hline Referências à semi-realidade & $(3)$ & $(4)$ \\
\hline Referências à realidade & $(5)$ & $(6)$ \\
\hline
\end{tabular}

Fonte: Skovsmose (2008, p. 23)

O ambiente do tipo (1) é caracterizado pela proposição de exercícios, abordando tópicos ou temas da Matemática pura, e apresentados com comando como "faça", "determine", "calcule". Aproxima-se ou descreve os ambientes que problematizamos neste texto. Ao adotar a perspectiva da Educação Matemática Crítica para desenvolvimento do projeto, idealizamos a constituição de ambientes como em (6).

Um cenário para investigação, na concepção de Skovsmose (2008), constitui-se como um

\footnotetext{
1 Premissa de que para aprender matemática os alunos deverão repetir técnicas e métodos sem levar em consideração a relevância de determinados conteúdos, aceitando portanto, todos os dados do exercício e seu enunciado sem questioná-lo, sendo todas suas informações suficiente para resolução e que existe uma e somente uma resposta correta.(ver, por exemplo, SKOVSMOSE, 2000).
} 
ambiente de aprendizagem "que convida os alunos a formular questões e a procurar explicações" (p. 21). Para o autor, a noção de ambiente de aprendizagem não se reduz a espaço físico e recursos materiais onde a atividade acontece. Tem significado amplo e inclui participantes e relações entre os mesmos, questões colocadas, tecnologias e quaisquer alterações que eventualmente ocorram durante seu desenvolvimento (ver SKOVSMOSE, 2008; ARAÚJO, 2009; BARBOSA, CALDEIRA e ARAÚJO, 2007). Dito de outro modo, idealizamos constituir um cenário para investigação envolvendo os alunos em um projeto de modelagem sobre sua realidade cotidiana. Além de romper com o paradigma do exercício, nossa expectativa é a de atuar transformando os papeis passivo dos participantes e de autoridade pré-estabelecida do professor, característicos de uma sala de aula tradicional.

Nesse artigo trazemos resultados de pesquisa em um ambiente que foi idealizado como o descrito acima. $O$ foco são as reflexões matemáticas que podem emergir em um ambiente de Modelagem Matemática que se constitui como cenário para investigação. Nossa hipótese é que, uma vez em contato com uma situação-problema, o ambiente de aprendizagem pode constituirse como desencadeador da produção do conhecimento matemático. Ou, em outras palavras, uma atividade de Modelagem, proposta como um convite para investigação, pode abrir espaço para que os alunos usem e construam novos conhecimentos (ver, por exemplo, BARBOSA, CALDEIRA e ARAÚJO; ROSA e OREY, 2007).

Organizamos este artigo em cinco seções. A segunda e terceira seções apresentam 0 planejamento, a metodologia e o desenvolvimento do projeto de pesquisa. $A$ análise dos dados produzidos durante os encontros compõe a quarta seção. Na quinta e última seção discutimos os resultados, trazendo considerações finais.

\section{Planejamento, procedimentos metodológicos e metodologia de pesquisa}

Para o desenvolvimento da pesquisa planejamos uma intervenção em sala de aula, em horário extra turno, envolvendo um grupo de seis alunos voluntários em projetos de modelagem, que foram desenvolvidos em oito encontros, com duração média de uma hora. Participantes são alunos do nono ano de uma escola pública.

Instrumentos metodológicos consistiram de anotações em um caderno de campo e observações em sala de aula. O material produzido foi complementado por questionários, observação direta e rodas de conversas, gravadas com grupos de alunos, que foram integralmente transcritas para serem analisadas. 
A análise do material focou as reflexões matemáticas que emergem das interações dos participantes durante o desenvolvimento de projeto de modelagem, nos momentos do planejamento e realização da(s) atividade(s) programada(s), bem como durante os relatos dos alunos sobre a forma como planejaram e realizaram a atividade. A atenção foi voltada às soluções apresentadas pelos participantes durante a transição da situação-problema para os conceitos matemáticos e às possibilidades e limites do projeto desenvolvido na formação matemática crítica dos participantes.

A Metodologia da Investigação Crítica, como proposta em Skovsmose e Borba (2004), foi adotada para desenvolvimento da pesquisa. Referenciada em uma pedagogia do conflito e do diálogo, esta metodologia pressupõe que a pesquisa crítica tem a finalidade de gerar mudanças no contexto da sala de aula, e de abordar questões que estão em sintonia com as da Educação Matemática Crítica, com caráter político.

Skovsmose e Borba (2004) abrem novas possibilidades à pesquisa sobre tais alternativas a partir de um processo dinâmico e cíclico descrito por Ação-Observação - Reflexão - Mudança - Planejamento - Ação. Caracterizam a natureza da pesquisa e esclarecem informações relevantes para a mesma, analisando três situações. Estas são denominadas pelos autores como Situação Atual (Current Situation — CS), Situação Imaginada (Imagined Situation — IS) e Situação Arranjada (Arranged Situation - AS).

A Situação Atual é aquela que ocorre antes do experimento educacional acontecer, antes da coleta de dados por meio de observações e anotações. O que leva o pesquisador a pensar em alternativas para reverter o desinteresse dos alunos sobre um determinado assunto é uma idealização de possibilidades, denominada Situação Imaginada (IS). Já a Situação Arranjada (AS), é uma alternativa colocada em prática que emerge de uma negociação entre os participantes (alunos, professores, administração da escola, responsáveis).

A pesquisa crítica organiza as três situações atribuindo-Ihes igual importância (Figuras 1 e 2) nas observações, narrativas ou outros insumos para o processo de pesquisa.

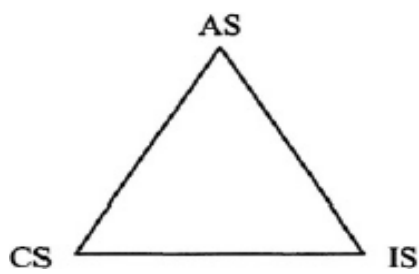

Figura 1: Modelo de Investigação Crítica (BORBA e SKOVSMOSE, 2004. p. 7)

Os autores definem diferentes processos permeando a pesquisa crítica, fazendo com que 
todas as situações se relacionem. Estes são denominados Imaginação Pedagógica (Pedagogical Imagination - PI), Organização Prática (Pratical Organization - PO) e Raciocínio Exploratório (Explorative Reasoning - ER), estabelecidos conforme a Figura 9.

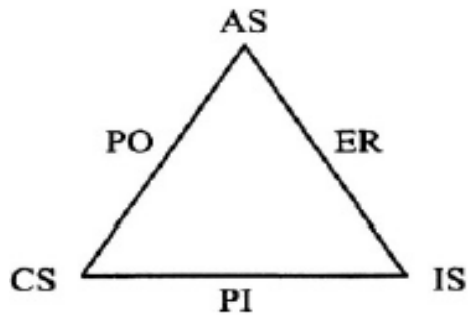

Figura 2: Modelo de Investigação Crítica com Processos que podem ser incluídos (BORBA e SKOVSMOSE, 2004. p. 8)

A imaginação pedagógica $(\mathrm{PI})$ diz respeito à relação entre a Situação Atual e Situação Imaginada, estabelecida pelos processos que apoiam a criação de situações imaginadas.

Já o relacionamento entre a Situação Atual e a Situação Arranjada é estabelecido a partir de uma Organização Prática (PO), que consiste de práticas, planejamento de atividades necessárias para estabelecer uma situação arranjada. Várias decisões ao planejar a Situação Arranjada são tomadas em conjunto com a direção da escola, com professores das turmas envolvidas no projeto, e com os alunos voluntários que participarão dos encontros. E o Raciocínio Exploratório (ER) reside no processo analítico envolvido ao reconsiderar a Situação Imaginada a partir das experiências obtidas na Situação Arranjada. Permite, portanto, a viabilidade da imaginação pedagógica bem como a análise de elementos inovadores de organização prática, seu potencial e suas limitações.

A partir daí a qualidade da pesquisa se dá na qualidade da interação entre esses processos e possibilidades de pesquisa. Nesse sentido, nas pesquisas críticas, os agentes participantes não podem ser vistos como meramente objetos de estudos. Tais objetos são, de fato, as relações que surgem no desenvolvimento do projeto e a qualidade da imaginação pedagógica, por exemplo.

Investigar possibilidades significa pesquisar com alguém as qualidades do processo de imaginação pedagógica, organização prática e do raciocínio exploratório. Isso ocorre a partir da cooperação entre os participantes, já que fazer uma crítica significa especificar que "algo pode ser diferente". Da mesma forma, fazer pesquisa crítica significa especificar o porquê e como "algo pode ser diferente". Em nosso caso, significa especificar como o ambiente em sala de aula pode ser diferente. 


\section{Desenvolvimento do projeto de pesquisa}

Dando início à pesquisa, o pesquisador, primeiro autor desse artigo, descreve a Situação Atual a partir de sua experiência com as práticas da Matemática escolar na instituição que permitiu o campo para a pesquisa, onde ele atua como professor. A sala de aula de Matemática reproduz os ambientes descritos em Skovsmose (2008) como constituídos no Paradigma do Exercício, tendo a Matemática como referência (ver Quadro 1). A professora regente da turma selecionada para desenvolver o projeto contribui durante a Organização Prática, que resulta na idealização da Situação Imaginada. Ela traz informações, suas impressões e dificuldades para pensar alternativas que possibilitassem ir além da mecanização na resolução de exercícios, ajudando os alunos a desenvolver o pensamento matemático. Informa-nos de que um dos principais problemas da turma com a Matemática era a transformação da linguagem natural para a linguagem matemática, obstáculo identificado com frequência na literatura de pesquisa evidenciando as dificuldades dos alunos com a interpretação de enunciados de problemas matemáticos, em especial os conhecidos como problemas com palavras.

A prática em sala de aula que concebemos como Situação Imaginada, propõe a constituição de cenários para investigação. Buscamos uma mudança na perspectiva pedagógica do paradigma do exercício para a constituição de um cenário para investigação, propondo um projeto de modelagem na perspectiva da EMC. Dito de outro modo, em processo de Imaginação Pedagógica delineamos como objetivo elaborar junto com os alunos um projeto de Modelagem Matemática cuja temática seja concebida, investigada, analisada, concluída e compartilhada por eles, tendo ao longo do percurso a intenção de refletir com esses estudantes sobre a Matemática que estão praticando e como esta pode ajudar a resolver algum problema que por ventura venha a surgir.

Em Raciocínio Exploratório a partir da Situação Imaginada, nossa avaliação sobre os limites e possibilidades ao planejar a Situação Arranjada, nos levou à expectativa de elaborar uma atividade de Modelagem Matemática na Educação Matemática como um ambiente de aprendizagem que aproximasse a realidade dos alunos e os conceitos matemáticos, por meio de representações múltiplas - em gráficos, tabelas, números, e também transição de números para textos -, contribuindo para uma formação dos estudantes como agentes ativos, reflexivos e críticos, como proposto em Barbosa (2001). Esperávamos constituir cenários que propiciassem aos alunos experiências por meio da Matemática, em que eles desenvolvessem e exercessem sua autonomia e crítica perante a sociedade a partir de atividades que possibilitassem a investigação, reflexão e o diálogo. Por fim, entendemos que o projeto e portanto, a pesquisa, poderia ter tomado 
qualquer rumo, tendo em vista que o tema foi de escolha dos alunos, cabendo ao professor somente a orientação.

\section{A Situação Arranjada}

Em Organização Prática, planejamos o desenvolvimento de um projeto de modelagem em oito encontros, dentre os quais seis seriam presenciais e dois para pesquisa individual ou em grupos em casa ou na escolar, forra do horário dos encontros. Convidamos os alunos para participar das atividades, que seriam realizadas no extra turno. Ao final de cada encontro, discutimos e preparamos o encontro seguinte, sempre abertos a novos elementos que emergiam nas interações entre participantes durante as atividades, que eventualmente levassem até mesmo a alterar a proposta inicial idealizada. No primeiro contato apenas cinco alunos compareceram: Sara, Ana, Julia, Tereza e Augusto. À exceção de dois encontros presenciais, o grupo se manteve presente em todos os oito encontros. Os nomes dos estudantes são fictícios.

Como em Sousa e Rego (2009), propusemos uma entrevista no primeiro encontro. Aplicamos em seguida um questionário para ser respondido por escrito, com o objetivo de elaborar o perfil do grupo, buscando "conhecer melhor o aluno, seus hábitos de estudo, suas concepções sobre a matemática ...." (SOUSA e REGO, 2009, p. 8). Especificamente, em nossa pesquisa, além do contexto cultural, familiar e social dos alunos, buscamos conhecer os motivos do interesse em participar do projeto. A entrevista focou as concepções sobre a Matemática, sobre a Matemática e sua relação com o mundo, e sobre Modelagem Matemática. Nossa conjectura é a de que os alunos teriam resistência a uma abordagem alternativa para trabalhar com o conhecimento matemático, e a intenção era a de acompanhar e analisar sua relação com o conhecimento ao longo do projeto.

Encerramos cada encontro presencial com rodas de conversa, buscando sintetizar ou propor atividades para o encontro seguinte.

\subsection{0 perfil dos participantes}

A trajetória acadêmica dos participantes é muito similar. Todos estudaram em escolas públicas, moravam geralmente com os pais, e tinham as mais diversas expectativas para o futuro e aspirações profissionais. A maioria - 4 em 5 participantes - considera a Matemática difícil, e questiona a utilidade de certos temas matemáticos ensinados na escola -3 em 5 participantes. 
Todos foram unânimes em afirmar que a Matemática é importante; embora sem justificar por quê. Inicialmente, a relação da Matemática ensinada na escola com o cotidiano, na visão daqueles estudantes, pareceu-nos restrita a operações financeiras e às quatro operações: "Ahh...para fazer troco, fazer a conta no banco. Aí vai lá ver o extrato e aí tu usa, entendeu?" (Tereza, primeira entrevista). Os participantes não acreditam ter utilizado a Matemática para tomar nenhuma decisão, mesmo reconhecendo seu uso em transações financeiras.

Ainda no primeiro encontro, uma das participantes, Fernanda, cujo irmão é aluno de um curso de Engenharia, esclarece que a Matemática ensinada na escola vai ser usada futuramente "... porque meu irmão usa ... ele faz faculdade". Por outro, lado Sara e Augusto, que não se manifestam durante o diálogo inicial, aparentam ter desenvolvido uma relação diletante com o uso da Matemática:

Sara: Os meus passos na rua, professor, às vezes eu conto... tipo ... é

... uma vez eu passei por ali, ai eu conto 100 passos ...

Neste momento, o pesquisador percebe que Augusto não está participando do diálogo e busca incluí-lo.

Pesquisador: E você, Augusto?

Augusto: Eu gosto de medir as coisas

Pesquisador: Qual a importância de medir as coisas para você?

Tereza: Pra saber o tamanho

Sara: quantidade de metros que tem, sei lá

Augusto não se manifesta, atropelado pelas respostas simultâneas das colegas. 0 pesquisador, que fez uma intervenção crítica, não retoma a pergunta, e o episódio se encerra aí. (Excerto do primeiro encontro)

Ao expressar a razão de seu interesse em realizar o projeto, os participantes destacam sua curiosidade, seu interesse em vivenciar o novo e ter novas experiências com o desconhecido. $\mathrm{Na}$ visão de Ana, em entrevista no primeiro encontro, os alunos que se voluntariaram a participar do projeto tinham expectativas de "ver como a Matemática está nas coisas e é muito importante aprender coisas simples além de contas", referindo-se a cálculos com números e operações básicas. Os alunos estavam dispostos a realizar as atividades propostas, porém, devido a restrições de horário, só foi possível realizar encontros uma vez por semana.

Em síntese, nossa Situação Arranjada envolveu um grupo de participantes cuja maioria 
- 4 em 5-declara ter dificuldades com a Matemática ensinada na escola, que a entendem como um mecanismo para resolver contas e cuja utilização no cotidiano está restrita a movimentações financeiras. Os participantes exprimem três visões comuns e distintas sobre a Matemática que se ensina na escola: grande parte do que se ensina não tem utilidade e não deveria ser ensinada; 0 que se ensina e não se utiliza no momento será utilizado no futuro; o que se aprende na escola traz prazer.

Ainda assim aceitaram participar do projeto porque tinham interesse em vislumbrar como a Matemática poderia ser diferente e de que modos seu entendimento sobre ela poderia mudar. Vale destacar o papel do pesquisador buscando incluir nas interações todos os participantes do projeto.

\subsection{Concepções iniciais sobre Matemática}

Ao responder sobre o que entendiam por Matemática, todos os participantes se remeteram, não ao conhecimento matemático, mas ao modo como era ensinado/aprendido. Em nossa análise, tal percepção parece natural, pois corresponde à experiência dos participantes com a Matemática: pelas respostas dos alunos às questões sobre Matemática e relação com 0 cotidiano, a Matemática pareceu-nos reduzida à Matemática que é praticada dentro da escola. Como era esperado, e correspondendo à prática declarada pela própria professora, a percepção sobre Matemática evocada pelos participantes refletiu a abordagem do conteúdo em sala de aula, identificando-o com a repetição exaustiva de exercícios e utilização de procedimentos para resolvê-los. Tais procedimentos estavam se tornando cada vez mais complexos no momento da vida acadêmica dos estudantes, até mesmo em termos operacionais. Esta observação é inferida da declaração da aluna Tereza quando, no primeiro encontro, ela descreve que costumava gostar de Matemática, "mas agora que está dificultando minha mente na tal Fórmula de Bhaskara". Seu desabafo sugere a falta de sentido do mecanismo utilizado para encontrar as raízes de uma equação do segundo grau e/ou a complexidade das manipulações que passam a ser envolvidas.

\subsection{Reflexões iniciais sobre a Modelagem Matemática}

Durante a roda de conversa no primeiro encontro, a discussão sobre as percepções dos participantes a respeito da importância de se estudar Matemática foram articuladas a questões a respeito de suas percepções sobre Modelagem Matemática. 
Tereza e Julia confirmam que já ouviram falar de modelagem, concordando com 0 entendimento bastante compartilhado entre alunos da escola básica de que "... modelagem pra mim é massinha".

Como no caso da percepção evocada sobre a Matemática, as participantes se remetem às suas experiências relacionadas ao nome do conceito, modelagem, trazendo as ideias que elas relacionam a este nome. Aparentemente há duas visões distintas sobre Modelagem Matemática e sobre Matemática nesta roda de conversa - aquela que entende a Matemática como préexistente, dentro da "coisa" e a que percebe aquele conhecimento como um instrumento ou meio que pode ser utilizado para "modelar usando a Matemática". O pesquisador aproxima a noção de modelagem a partir das noções evocadas, e busca ampliar os diversos entendimentos a partir dele

$P:$ É, de certa forma é... você vai pegar uma determinada coisa, e vai transformar ela em uma determinada coisa, vai modelar ela. Não é isso?... a gente vai pegar um determinado assunto, e vai modelar ele, de acordo com a Matemática, ou usando a Matemática.

O pesquisador busca consolidar as duas perspectivas, reforçando a ideia de uso da Matemática, e de leitura matemática do mundo. Prosseguindo a discussão, Júlia traz o futebol como exemplo de um jogo possível de ser "modelado", sem ainda ter clareza do que realmente seria tal processo.

Julia: Tipo futebol.

P: Pode ser. A gente pode pensar que Matemática tem atrás do futebol.

Tereza: O campo, medida.

Ana: Posição dos jogadores

Tereza: Posição de cada um, a diferença de metros de cada um.

$P$ : mais o que?

Augusto: o gol (Excerto do primeiro encontro)

Aqui os participantes arriscam primeiras leituras sobre um jogo de futebol, lançando um olhar matemático para elementos do jogo. Referiram-se à medida do campo, à posição no plano do campo, distância entre jogadores e o gol. Tais leituras são todas sugestões válidas para propostas de modelagem.

Em nossa análise, destacamos que a partir das intervenções e interações na roda de 
conversas e de reflexões dos participantes sobre o conceito de Modelagem Matemática emergem reflexões sobre a Matemática e seu uso que transforma totalmente a reação inicial dos participantes sobre o jogo de futebol, evidenciando que temas como este também poderiam ser estudados sob um olhar matemático, em um projeto de Modelagem Matemática. Mais do que isto, as reflexões sobre Modelagem Matemática ampliaram as reflexões iniciais sobre o conhecimento matemático dos participantes, no decorrer de um mesmo encontro. Não estamos afirmando que os estudantes perceberam a possibilidade de entender o mundo com um olhar matemático durante este breve diálogo; mas, sim, que as reflexões sobre Modelagem Matemática surgem como desencadeador da consciência sobre tal possibilidade e de ferramentas matemáticas para empreendê-la. Em destaque à intervenção do pesquisador que, embora instigando a busca por uma "Matemática que tem atrás do futebol" como se o conhecimento fosse objeto pré-existente, se fez entender pelos alunos e estimulou relações entre aspectos do jogo que podem ser mensurados, quantificados e geometrizados.

\subsection{Transformações ao longo dos encontros}

Ao perceber o interesse dos estudantes sobre o tema, o pesquisador propõe realizar um projeto de modelagem com a temática Futebol. Encontra resistência por parte de Augusto e soluciona o impasse propondo que cada um realize um projeto sobre esportes, de forma geral, para ser discutido no próximo encontro.

Em roda de conversa no segundo encontro, os participantes apresentaram resultados de sua pesquisa trazendo possibilidades de leituras para desenvolver um projeto de Modelagem Matemática. Tereza e Ana abrem possibilidades para perspectivas geométricas - formas do corpo em movimento na Ginástica, e numéricas - cálculo do pulo e do tempo. 0 aspecto de gasto de energia e medidas é o olhar matemático que Ana propõe para estudar o atletismo, o que poderia resultar em modelos de funções ou em projetos interdisciplinares. De modo semelhante a Augusto, que propôs estudar a Natação, Tereza situa a prática esportiva do futebol em contexto mais amplo, dos benefícios que ela traz para a saúde do indivíduo. Antecipa-se ao pesquisador, trazendo aspectos da Matemática que ela percebe sendo usados - a medida do campo e cálculos sobre velocidade de deslocamento dos jogadores são as principais formas de interpretar a Matemática no futebol. Por fim, Jéssica diz que não pesquisou muito, mas pesquisou sobre Patinação. O tempo e a velocidade e, portanto, o contexto de medida, é novamente mencionado como possibilidades de leitura do esporte. 
Uma intervenção do pesquisador leva Julia, que propôs a patinação como tema para o projeto de modelagem, a relacionar o equilíbrio como um aspecto importante.

Pesquisador: E você consegue pensar em alguma Matemática através da patinação?

Julia: Tempo

Tereza: Tudo tem que ter tempo.

Ana: Velocidade.

Pesquisador: Não dá pra correr muito, tem que ter o tempo pra parar, não é?

Julia: Equilíbrio, professor.

Pesquisador: Equilibrio? Qual a Matemática que se tem no equilíbrio, se a gente for parar pra pensar?

Ana: Divisão do peso do corpo. Não sei.... (Excerto do segundo encontro)

Como no encontro anterior, a intervenção do pesquisador sugere um foco em uma Matemática pré-existente, ao invés de uma leitura matemática da patinação, focando a patinação, o que é compreendido pelos participantes. Da leitura de Ana do equilíbrio como "divisão do peso pelo corpo", o pesquisador intervém e sugere o conhecimento geométrico de simetria como uma leitura matemática possível de aspectos do esporte. Discute o conceito de equilíbrio como distribuição equitativa do peso, possibilitando analogia com noção geométrica e associações com aspectos similares em outros esportes.

Pesquisador: A gente pode pensar no equilibrio como uma espécie de simetria. Não é? É que tem o mesmo peso pra um lado e pro outro.

Ana: Isso.

Pesquisador: Mesmo peso pra um lado, mesmo peso pro outro. Se você coloca um pouco mais de peso pra um lado, você cai, se coloca pro outro, também.

Tereza: É igual na corda bamba, né?

Pesquisador: Exatamente. 
Ana: É igual a bicicleta.

Pesquisador: Exatamente. (Excerto do segundo encontro)

Como em uma síntese do que fora discutido, Augusto se expressa pela segunda vez conversa: "Tem que tá centralizado."

Este excerto exemplifica um momento em que os estudantes começam a expandir sua percepção passando a incluir concepções matemáticas mais abstratas, tais como a ideia de simetria. Exemplifica a possibilidade aberta pela alternativa pedagógica criada, da Modelagem Matemática, para discutir conceitos matemáticos. Há momentos, interessantes como este, em que os participantes são levados a concluir que determinados conhecimentos matemáticos da escola seriam utilizados em níveis mais avançados, ou que a Matemática requerida para resolver 0 problema seria muito complicada, abandonando o projeto. Vale observar a questão sobre a zona de conforto do pesquisador/professor, se iniciante ou inexperiente em sua atuação na área de modelagem, não sendo capaz de se atrever a mergulhar no desconhecido.

No caso desta pesquisa, um novo papel docente gera no pesquisador preocupação e insegurança, pois está inserido em um contexto que demanda mudanças. Busca manter-se nos limites do que conhece, não se arriscando a trabalhar com desafios, com novas situações, com 0 imprevisível, com o inesperado e com a perda de controle (BORBA e PENTEADO, 2010).

Por outro lado, ao adotar como Barbosa (2004), uma perspectiva crítica sobre o uso da Modelagem Matemática na Educação, Araújo (2009) propõe como ponto de partida para as atividades uma situação real, que tenha relevância política e que faça parte do cotidiano dos alunos. Com essa intenção o pesquisador propõe um tema cuja abordagem Ihe traz segurança, relacionado a esportes, trazendo uma pesquisa estatística sobre sedentarismo.

Pesquisador: Que tipos de situações a gente pode pesquisar usando a Matemática, relacionada a esportes?

Tereza: Como assim.

Pesquisador: Por exemplo, segundo a pesquisa que a gente viu, metade da população é sedentária. Vocês acreditam nisso?

Ana: Eu acredito.

Julia: Eu acredito.

Tereza: Eu acredito que até mais da metade. (Excerto do segundo encontro) 
A sensibilidade do pesquisador em identificar possíveis indícios da Ideologia da Certeza (BORBA e SKOVSMOSE, 2001), que apresenta a Matemática como um conhecimento capaz de julgar decisões humanas e de ser inquestionável, levam-no a instigar reflexões sobre tais dados.

Pesquisador: E como a gente pode confirmar isso?

Ana, e Julia: Porcentagem (Excerto do segundo encontro)

Os participantes começam a levantar sugestões que podem levar à elaboração de um questionário para traçar o perfil da prática de esportes na comunidade escolar. Ao colocar questões, sinalizando o aceite ao convite feito pelo pesquisador, iniciam a constituição de um ambiente que se aproxima do de um cenário para investigação (SKOVSMOSE, 2000).

Tereza: A gente vai pegar as pessoas, e vai perguntar e vai pesquisar sobre aquilo e fazer um gráfico. A gente tira um dia, fica no auditório, e reúne cada tudo daqui de tarde, e aí a gente vê.

Pesquisador: Tá, essa parte a gente vê depois. Mas o que vocês iriam fazer?

Tereza: A gente ia perguntar sobre os esportes.

Ana: Sobre as atividades que elas gostam (Excerto do segundo encontro)

Tereza e Julia passam a sugerir as estratégias de análise dos dados obtidos por meio de porcentagens e gráficos. "Vamos anotar isso?" diz o pesquisador, intervindo na organização e planejamento da pesquisa. Ao mesmo tempo, o pesquisador se afasta e permite que os alunos explicitem suas propostas, trazendo um olhar matemático explícito e espontâneo sobre o tema.

Julia: E a gente ia montar um gráfico com o nome de alguns esportes.

Tereza: Botar a porcentagem

Ana: E ver como ficaria (Excerto do segundo encontro)

O pesquisador intervém abrindo outras possibilidades

Pesquisador: Coisas que são relevantes pra pesquisa de vocês. Que vocês querem investigar.

Ana: Qual esporte gosta mais.

Tereza: O que você faz no seu dia a dia? 
Pesquisador: Tipo atividade física?

Pesquisador: Idade e sexo vocês acham relevante?

Tereza: Idade

Ana: Sexo eu acho que não precisa.

Pesquisador: A gente viu que tem uma diferença entre prática de esportes por homens e mulheres.

Julia: Sexo é relevante. (Excerto do segundo encontro)

Em seguida o pesquisador sugere incluir a utilização do Índice de Massa Corporal (IMC) e uma questão sobre a frequência com que a pessoa pratica esportes.

Os estudantes, que em sua maioria não sabiam o que era tal índice, concordam em utilizálo, introduzindo no projeto uma medida que vem sendo utilizada internacionalmente. Relacionado à questão de obesidade, o IMC é um uso reconhecidamente importante da Matemática.

Em certo momento, o pesquisador pergunta “Mais alguma coisa, gente?". Tereza devolve ao pesquisador a questão sobre o que pesquisar, sugerindo esgotamento do que o grupo considera importante investigar. Pelo menos, no momento.

Tereza: Pensa aí, professor, o que mais a gente pode colocar?

Pesquisador: Não sei.

Julia: Tem quantas perguntas?

Pesquisador: A gente vai fechar aqui com essas perguntas. (Excerto do segundo encontro)

Encerrada a elaboração do questionário, os participantes prosseguem com a antecipação, espontânea, de uma discussão sobre estratégias de organização para execução da pesquisa. Os estudantes propõem que a análise dos dados seja dividida a partir das idades dos entrevistados.

Ana: A gente vai pesquisar com as turmas, do menor pro maior

Pesquisador: Isso, eu tinha pensado que nem ela falou aqui, pegar $6^{\circ}$, $7^{0} 8^{\circ}$

Ana: Do mais novo pro... as idades crescendo.

Julia: A gente pode dividir idade.

Tereza: É, de idade, tipo, de 15 a 18 anos 
Ana: Não, de 10 a... de 11 a 13 uma coisa, de 13 a 15 outra coisa. De

15 a 18 outra coisa.

Pesquisador: Isso, de pegar intervalor de 13 a...

Tereza: $\dot{E}$.

Julia: Tipo de 3 em 3. Tipo de 13 a 16, e de 16 a 19.

Ana: Não, de 13 a 16 e de 17 a... não pode ter duas vezes 16. (Excerto do segundo encontro)

Aqui evidenciamos o exercício da autonomia dos estudantes principalmente ao discutir a elaboração e organização do projeto, metodologia que utilizarão e quais serão estratégias para análise do material coletado. Sempre apoiados pelo pesquisador, que busca intervir sem tolher a liberdade dos alunos no projeto. Analisamos o processo descrito até aqui tendo como referência a Educação Matemática Crítica, apresentando dados que evidenciam o desenvolvimento de um processo de questionamento, elaboração de problemas, análise de soluções, bem como de validação dos procedimentos adotados e resultados encontrados durante as aulas de Matemática (ARAÚJO, 2007).

Planejado para acontecer em três dias, no contexto da escola e em seu entorno, o que denominamos terceiro encontro consistiu na aplicação do questionário. As respostas a 85 questionários são discutidas e preparadas para serem analisadas durante 0 quarto encontro. Como anteriormente, os estudantes criam modos para organizar os dados coletados, propondo modelos em linguagem matemática como referência para descrever, entender e criticar a realidade.

Pesquisador: E como a Matemática vai entrar aí?

Tereza: Porcentagem.

Beatriz: Porcentagem tá bom, mas gráfico ficaria legal também né?

Pesquisador: Como vocês acharem melhor...

Sara: Primeiro a gente separa as idades, depois a gente separa sexo

Ana: depois pessoas que fazem e não fazem exercícios

Pesquisador: E agora, como vamos chegar na porcentagem de homens

e mulheres que foram entrevistados?

Ana: Não é pegar o número de homens e dividir pelo total de 
entrevistados?

Tereza: é isso professor?

Pesquisador: Isso

Ana: E depois multiplica por $100 \quad$ (Excerto do quarto encontro)

O pesquisador sugere uso de calculadora para encontrar o valor da porcentagem. Ao calculá-la, a aluna Ana se surpreende com a resposta, um número decimal na tela da calculadora, exclamando "Ih, deu número decimal". Sugerindo a rotina no Paradigma do Exercício como expectativa, ela esperava um número inteiro como resultado. Assim, o cenário esperado foi modificado, de um contexto de resolução de questões usando a Matemática do paradigma do exercício para um cenário em que a referência é a realidade (SKOVSMOSE, 2000).

Ao ser enunciado, o procedimento para calcular a porcentagem abre espaço para discutir seu significado, embora no momento em questão tal significado se reduza ao de um procedimento para obter o resultado.

Julia: Agora multiplica por 100?

Pesquisador: Isso

Sara: 48,23

Pesquisador: \%

Ana: Ahh pra isso que usa o \%?

Pesquisador: Sim. Pra dizer que o valor tá sendo dividido por 100

Tereza: Entendi (Excerto quarto encontro)

Após a intervenção do pesquisador, Júlia, aparentemente, entende o procedimento para calcular uma porcentagem e por analogia o enuncia para o caso das mulheres. Embora sendo capaz de realizar os passos do processo, Ana não parece entender nesse momento a relação entre o número decimal e o que ela entendia por porcentagem. Ana parece se envolver em uma redescoberta dos significados da simbologia matemática.

Pesquisador: E agora? Para achar o percentual de mulheres

Julia: A mesma coisa, só que agora é 44 divido por 85

Ana: 0,517647...

Tereza: $51,76 \%$ (Excerto do quarto encontro) 
As alunas utilizam métodos conhecidos para representar em porcentagem uma informação que elas buscavam. Embora tenha sido proposto por elas mesmas, parece haver surpresa no que diz respeito à conceituação de 100\% como unidade, ou o todo, da comparação que está sendo feita.

Prosseguindo com a análise, as alunas tomam decisões metodológicas; como por exemplo a de descartar um questionário que estava todo em branco. Refazem os cálculos, ao perceberam que na verdade 47 mulheres e 37 homens haviam respondido as perguntas. Com autonomia, formulam questões e buscam soluções para as novas ideias não previstas anteriormente. Noções conceituais sobre porcentagem são abordadas em decorrência da discussão que é iniciada.

Ana: Professor, a gente pensou numa parada aqui... por exemplo... se a gente quiser separar as pessoas que não fazem exercícios com as que fazem, como que a gente poderia saber?

Pesquisador: Não entendi... vocês querem saber o que? Quantas mulheres não fazem exercícios tendo como ponto de partida o total de pessoas? Ou comparando as mulheres entre si?

Sara: Entre as mulheres

Pesquisador: Vai ser o mesmo procedimento. Vai ver o quantitativo total de mulheres.

\section{Tereza: 47}

Pesquisador: Desse total, ver quantas fazem e quantas não fazem.

\section{Tereza: Entendi}

Ana: 47 vai ser o novo 100\% (Excerto do quarto encontro)

A discussão, conceitual, traz o entendimento do significado do todo, ou do $100 \%$, naquele caso. No que segue, o pesquisador intervém, convidando os alunos a refletir criticamente sobre os resultados, fazendo comparações entre os diversos grupos estudados.

Pesquisador: Esse número aqui é muito alto, não acham? Quase oitenta porcento das mulheres entrevistadas não fazem exercício.

Tereza: Acho! Mulheres preguiçosas, né?

Ana: Agora vamos fazer o percentual de mulheres que fazem (Excerto 
do quarto encontro)

O pesquisador prossegue instigando os participantes a repensar novas formas de avaliar os dados, a partir da seleção de grupo específico.

Pesquisador: E aí, vão fazer como?

Sara: Ahh professor: 100 menos 76,59

Pesquisador: Isso aí. Mas porque não fazer a divisão?

Sara: Ahh, se você já tem o total de mulheres que não fazem, o restante faz.

Tereza: Vai dar 23,41\%. Muito menos da metade... a metade da metade.

(Excerto do quarto encontro)

Destacamos no excerto anterior o uso de mais de um procedimento para obter resultados, o que contribui para uma concepção da Matemática diferente da de conjunto de regras mecanizadas para resolver exercícios, com um único procedimento para se obter a resposta correta. O que vai de encontro ao paradigma do exercício. Em sua intervenção, o pesquisador sugere caminhos, sem determiná-los. Freire (1987) observa que o diálogo possibilita a reflexão e a partir daí a investigação e a ação. A postura crítica que o pesquisador busca desenvolver durante as interações ao longo das atividades pode ter desencadeado a avaliação da resposta encontrada em termos numéricos, feita por Tereza. Tais reflexões são importantes para uma discussão dos conceitos matemáticos que estão sendo usados. 0 diálogo entre participantes prossegue, como uma troca de ideias.

Pesquisador: E agora, vão fazer qual?

Tereza: Homens que fazem

Pesquisador: E qual total de homens que praticam algum esporte?

Ana: 26

Tereza: Então vai ficar 26 dividido pra 37.

Julia: 70,27

Pesquisador: E agora pra achar quem não faz?

Tereza: 100 dividido 70,27

Ana: Não cara, tá errado. É subtrair o total de homens pelo total que 
fazem

Tereza: 100 - 70,27! Agora sim. Bota aí, 29,63. (Excerto do quarto encontro)

Os resultados são obtidos por procedimentos análogos aos anteriores. O diálogo não sugere mecanização de procedimentos; além de indícios de colaboração entre participantes, que corrigem uns aos outros com um objetivo comum, que é o de desenvolver o projeto. $O$ pesquisador intervém não para declarar o que está certo ou errado, mas para levantar questões.

Pesquisador: Então comparando, quem pratica mais exercícios?

Julia e Tereza: Os homens.

Pesquisador: $E$ isso já era esperado ou vocês ficaram surpresas com isso?

Julia: Já era esperado.

Pesquisador: E observem, o número de homens que praticam esportes é 3 vezes maior do que o número de mulheres que fazem. (Excerto quarto encontro)

O pesquisador estimula a reflexão sobre o resultado obtido em contraste com resultado esperado. Por fim, estudantes que no primeiro encontro evocam concepções de Matemática restrita a operações financeiras e às quatro operações, passam a percebê-la explicitamente em diversas outras situações já experimentadas.

Tereza: Caramba, chegamos na matemática.

Sara: A gente sempre teve nela, só não sabia entender.

Pesquisador: E agora, que pergunta vocês vão analisar?

Tereza: A nove [Pergunta que se referia aos benefícios da prática de exercício] (Excerto quarto encontro)

Reafirmando o papel desempenhado como participante do grupo, o pesquisador intervém, coloca questões e estimula os participantes, deixando-os livres para fazer escolhas. Contribui assim para o desenvolvimento de sua autonomia. Tereza expressa sua opinião sobre a prática de esportes do sexo feminino e não parece surpresa com os valores encontrados. Embora Tereza já estivesse em contato com a Matemática desde o início do encontro, ela parece surpresa ao ver nos dados uma relação entre a prática de esportes realizadas por homens e por mulheres. 
Após a conclusão do trabalho, o pesquisador sugere elaborar formas para divulgar o que foi feito. Ana propõe que gráficos pode ser outra forma de análise de dados, e Sara propõe a realização de um texto para discussão dos dados.

Pesquisador: Com esses dados aqui no próximo encontro nós vamos discutir o que vamos fazer com isso e depois discutir esses resultados. O que vocês acham?

Ana: Sim, podemos montar gráficos.

Tereza: É verdade.

Sara: E também poderíamos fazer um texto sobre essa pesquisa.

Pesquisador: Vamos discutir essa ideia. (Excerto do quarto encontro)

Além destas formas de representação, os estudantes propõem a confecção de maquetes sobre cada esporte abordado como estímulo à prática de exercícios, acompanhadas das regras respectivas de cada jogo. As maquetes acompanhariam cada material produzido durante os encontros. Vale comentar que incluir a escrita de um texto sobre a pesquisa é surpreendente, e é proposta trazida por uma estudante. Sugere o envolvimento dos participantes com a proposta e um amadurecimento potencial que não é percebido na sala de aula tradicional.

Os demais encontros referem-se à elaboração do material produzido no projeto de modelagem sobre prática de esportes para apresentação na Feira de Ciências da escola. Dado 0 escopo deste artigo, não trazemos aqui nossa análise do material empírico referente a esses momentos por acreditarmos que já temos os argumentos para discutir a experiência realizada.

\section{Considerações}

Iniciamos a pesquisa com a intenção de investigar que reflexões matemáticas podem emergir em um ambiente de Modelagem Matemática que se constitui como cenário para investigação. Dos resultados afirmamos que as discussões sobre Modelagem Matemática e as atividades realizadas desencadearam reflexões sobre o conhecimento matemático, entendido aqui de modo amplo como incluindo sua importância, sua relação com o cotidiano e seu uso, ao mesmo tempo que contribuíram para a formação crítica e política dos estudantes.

Das percepções iniciais dos participantes sobre o conhecimento matemático, a partir da análise do material empírico produzido ao compor o perfil dos estudantes, destacamos perspectivas que não dissociam aquele conhecimento da prática com a Matemática escolar. Dito 
de outro modo, a Matemática escolar, imbricada ao modo como é ensinada, representa a experiência dos estudantes com aquele conhecimento. Confirmando a prática em sala de aula de Matemática declarada pela professora da turma, o conhecimento matemático é percebido pelos alunos como um conjunto de regras a serem mecanizadas, cujo significado se reduz a entender como fazer (FIORENTINI, 1995; PONTE e QUARESMA, 2016). Tanto a descrição da experiência dos alunos quanto a prática declarada pela professora remetem à uma Matemática que é trabalhada no paradigma do exercício, corroborando uma concepção absolutista da Matemática (BORBA e SKOVSMOSE, 2001; SKOVSMOSE, 2008)

Em tal contexto, as percepções iniciais expressas pelos estudantes sobre a Matemática e seu uso no cotidiano a reduzem às quatro operações e movimentações financeiras. Declaram ainda que nunca a utilizaram em tomada de decisões. Curiosamente, parece-nos que nem para decidir sobre compra de um ou outro produto em um supermercado. Mais curioso ainda é que mesmo assim, destacam a Matemática como importante de ser estudada; o que é senso comum em nossa cultura, mesmo que não saibamos justificar o porquê. Tão comuns quanto estas são as percepções de alguns participantes de que a escola ensina mais do que precisamos saber sobre Matemática, enquanto outros acreditam em um uso futuro do conhecimento aprendido. Dois dentre os estudantes expressam relações lúdicas ou diletantes com o conhecimento matemático. O grupo de participantes compõem assim um perfil que nos parece representativo dos estudantes, de um modo geral, em sua relação com a Matemática que é ensinada nas escolas.

Ainda no primeiro encontro, as reflexões sobre Modelagem Matemática também tiveram como referência as experiências vividas, desta vez com o uso do termo modelagem. Das relações emergem pelo menos duas concepções para Modelagem Matemática: a primeira sugere uma Matemática pré-existente, pronta e acabada, "dentro" do fenômeno a ser estudado; e a segunda sugere o uso da Matemática, como instrumento para entender e desenvolver um problema (SKOVSMOSE, 2000).

Das discussões iniciais, já no primeiro encontro, podemos destacar uma ampliação da visão dos participantes sobre a Matemática, desencadeada por reflexões sobre a Modelagem Matemática. Transformações são também evidentes ao longo do segundo e quarto encontros, destacadas em excertos em que o significado da Matemática e sua relação com o cotidiano, inicialmente restrita às quatro operações, passa a ser enunciada pelos alunos como medida, medida de espaço, posição, velocidade, movimento, simetria. Não afirmamos que a ampliação das perspectivas sobre a Matemática e seu uso foi aprendida ou ensinada, ou desenvolvida, durante as atividades com a Modelagem Matemática. Mas sim, afirmamos que a Modelagem Matemática 
pode desencadear transformações como estas, fazendo emergir o que já é conhecido, mas que não havia sido explicitado. Ou alternativamente, a partir da Modelagem Matemática os alunos desenvolvem um olhar que inicialmente não identificaria questões como da Matemática escolar, ultrapassando as fronteiras das concepções sobre a Matemática da escola, inclusive para além do seu uso cotidiano imediato com as quatro operações (ARAUJO, 2006; BARBOSA, CALDEIRA e ARAÚJO, 2007).

Transformações ao longo dos encontros trazidas em excertos do segundo e quarto encontros, em que os estudantes trabalham com uma Matemática já conhecida, basicamente a porcentagem, revelam discussão sobre conceitos, seu significado, proposição de modos distintos de resolver um mesmo problema. Emergem surpresas quanto ao aparecimento dos decimais durante o desenvolvimento do método. Há espaço em vários momentos para explicar o conceito em desenvolvimento - porcentagem. As atividades abrem espaço para rever e ensinar a matemática que está sendo utilizada².

É possível perceber o desenvolvimento de olhar matemático crítico sobre questões indiretamente a ela relacionadas; como por exemplo, quando os resultados da pesquisa sobre esportes são descritos e os conceitos matemáticos são retomados a partir de uma análise mais qualitativa dos resultados. Houve questionamentos sobre dados matemáticos absolutos $-\mathrm{a}$ pouca prática esportiva de pessoas com idade mais avançada, buscando razões que os justificassem - , a falta de tempo dos indivíduos nesta faixa etária por conta de atividades laborais, na percepção dos alunos. Foram citadas questões geopolíticas, no que diz respeito ao favorecimento da prática de esporte por conta de uma localização específica. 0 entendimento de um fenômeno não se reduz à uma abordagem puramente matemática do fato, ou seja, entendemos fazer parte da formação matemática uma discussão que vai além da Matemática. Educar matematicamente atravessa o modo de pensar sobre contextos sociais e políticos em que ela está presente. Por meio da modelagem, os estudantes foram capazes de pensar e relacionar os dados apresentados e problemas do seu cotidiano, sinalizando mudanças de postura como é o caso da falta da prática de esportes e dos prejuízos causados à saúde (BARBOSA, CALDEIRA e ARAÚJO, 2007)

Quanto a aspectos da educação crítica dos estudantes, destacamos o desenvolvimento da autonomia e reflexão dos participantes dos ambientes de aprendizagem constituídos, possibilitando entendimentos sobre a Matemática que transcendem o próprio conhecimento

\footnotetext{
${ }^{2}$ Nos questionamos, no entanto, se e o quanto o fato de investir nesses momentos poderia influenciar o fluxo da tarefa proposta.
} 
matemático como objeto de estudo. Por exemplo, nos momentos de transição da situaçãoproblema para os conceitos matemáticos, durante o quarto encontro, parte dos alunos uma proposta de organização e método para realização da tarefa, em que o pesquisador assume 0 papel de mediador. Vale mencionar que a identificação dos problemas cotidianos vivenciados pelos alunos e a sugestão de soluções foi um fator motivador e, também, desafiador para o bom andamento do projeto. Novamente a postura do pesquisador foi importante nesse processo, tendo em vista que este mediava os diálogos dando plena liberdade aos estudantes e buscava incluir todos nas discussões e decisões realizadas pelo grupo.

Por fim, o desafio ao idealizarmos a constituição de cenários para investigação sob perspectiva da Educação Matemática Crítica promoveu mudanças perceptíveis no ambiente investigado em relação ao cotidiano da sala de aula na escola pesquisada. Uma microanálise do ambiente de aprendizagem investigado poderia, talvez, revelar que cenários para investigação não foram constituídos na intervenção projetada, ou talvez revelar sua efemeridade, com alternâncias entre constituição e desconstituição de cenários (ver ARAÚJO et al., 2008). Por outro lado, nossa análise destaca no material empírico produzido momentos em que o ambiente idealizado outorga ao professor e alunos a redefinição de seu papel na sala de aula. O professor desloca-se do centro dos processos de ensino e de aprendizagem, do planejamento, da tomada de decisões, das responsabilidades e os alunos, compartilhando o processo, afastaram-se do papel de receptor passivo de decisões do professor.

Os alunos passaram a propor ações para desenvolvimento, organização e realização do projeto. Ou seja, passaram a participar de modo ativo de sua própria formação, podendo, a partir da autonomia adquirida, melhorar seu entendimento em Matemática (BARBOSA, 2007; ARAÚJO, 2006, 2010). De nossa análise, o ambiente de aprendizagem constituído durante o projeto de Modelagem Matemática é um ambiente dinâmico, já que apoia a elaboração de modelos matemáticos partindo de práticas discursivas que se originam nas interações sociais entre alunoaluno, professor-aluno e aluno-professor (BARBOSA, CALDEIRA e ARAÚJO, 2007). Estas práticas discursivas contribuem para desenvolver o raciocínio crítico por meio de discussões matemáticas, tendo como objetivo utilizar os objetos discursivos da linguagem matemática para a construção que denominamos significativa do conhecimento matemático.

Concluímos que os ambientes de aprendizagem propiciaram aos estudantes autonomia para a reflexão sobre situações cotidianas relacionadas com a Matemática. Reflexões estas que Ihes possibilitam (re) descobrir seus próprios entendimentos sobre a matemática e sobre o mundo que os cercam. 


\section{Referências}

ARAÚJO, Jussara de Loiola. Brazilian research on modelling in Mathematics Education. ZDM: Mathematics Education, v. 42, n. 2, p. 337-248, mar. 2010.

ARAÚJO, Jussara de Loiola. Modelagem Matemática no curso de Geografia: prática educacional e contexto de uma pesquisa. In: III SEMINÁRIO INTERNACIONAL DE PESQUISA EM EDUCAÇÃO MATEMÁTICA, 2006, Águas de Lindóia. Resumos do III SIPEM. São Paulo: Sociedade Brasileira de Educação Matemática, SBEM, 2006, p. 157-158.

ARAÚJO, Jussara de Loiola. Relação entre Matemática e realidade em algumas perspectivas de modelagem matemática na Educação Matemática. In: BARBOSA, Jonei Cerqueira; CALDEIRA, Ademir Donizeti; ARAÚJO, Jussara de Loiola. (Org.) Modelagem Matemática na Educação Matemática Brasileira: pesquisas e práticas educacionais. Recife: Sociedade Brasileira de Educação Matemática, 2007, p. 17-32.

ARAÚJO, Jussara de Loiola. Uma abordagem sócio crítica da Modelagem Matemática: a perspectiva da Educação Matemática Crítica. Alexandria, Florianopolis, v. 2, n. 2, p. 55-68. 2009.

ARAÚJO, Jussara de Loiola; FUSARO, Márcia Maria; LUZ, Cristian, Reis; RIBEIRO, Ana Regina. Efemeridade dos cenários para investigação em um episódio de sala de aula de Matemática com tecnologias. Zetetiké, Campinas, v. 16, n. 29, p.7-40, jan.jun. 2008.

BARBOSA, Jonei Carlos. A prática dos alunos no ambiente de Modelagem Matemática: o esboço de um framework. In: BARBOSA, Jonei Cerqueira; CALDEIRA, Ademir Donizeti; ARAÚJJ, Jussara de Loiola. (Org.) Modelagem Matemática na Educação Matemática Brasileira: pesquisas e práticas educacionais. Recife: Sociedade Brasileira de Educação Matemática, 2007, p. 161-174.

BARBOSA, Jonei Cerqueira. Modelagem Matemática: O que é? Por quê? Como? Veriatati, n. 4, p. 73-80. 2004.

BARBOSA, Jonei Cerqueira. Modelagem na Educação Matemática: contribuições para o debate teórico. In: 24a REUNIÃO ANUAL DA ANPED, 2001, Caxambu. Anais da 24a REUNIÃO ANUAL DA ANPED. Rio de Janeiro: ANPED, 2001, p. 1-12.

BARBOSA, Jonei Cerqueira; CALDEIRA, Ademir Donizeti; ARAÚJO, Jussara de Loiola. (Org.) Modelagem Matemática na Educação Matemática Brasileira: pesquisas e práticas educacionais. Recife: Sociedade Brasileira de Educação Matemática, 2007.

BORBA, Marcelo de Carvalho; PENTEADO, Miriam Godoy. Informática e Educação Matemática. 4. ed. Belo Horizonte: Autêntica, 2010.

BORBA, Marcelo de Carvalho; SKOVSMOSE, Ole. A ideologia da certeza em Matemática. In: SKOVSMOSE, Ole. A Educação Matemática Crítica: a questão da democracia. Campinas: Papirus, 2001, p. 127-148.

D’AMBROSIO, Ubiratan. Etnomatemática. São Paulo, SP: Editora Ática, 1990.

FIORENTINI, Dario. Alguns modos de ver e conceber o ensino da Matemática no Brasil. Zetetiké, Campinas, v. 3, n. 4, p. 1-37, 1995.

FREIRE, Paulo. Pedagogia do Oprimido. 42 ed. Rio de Janeiro: Paz e Terra, 2005. 
PONTE, João Pedro; QUARESMA, Marisa. Teachers' professional practice conducting mathematical discussions. Educational Studies of Mathematics, v. 93, n.1, p. 51-66, feb. 2016.

ROSA, Milton; OREY, Daniel Clark. Cultural assertions and challenges towards pedagogical action of an Ethnomathematics Program. For the Learning of Mathematics, v. 27, n. 1, p. 10-16, mar. 2007.

SKOVSMOSE, Ole. Cenários para investigação. Bolema, Rio Claro, v. 13, n. 14, p. 66- 91. 2000.

SKOVSMOSE, Ole. Desafios de reflexão em Educação Matemática Crítica. Papirus, 2008.

SKOVSMOSE, Ole. Educação Matemática Crítica: a questão da democracia. 4. ed. Papirus, 2001.

SKOVSMOSE, Ole; BORBA, Marcelo de Carvalho. Research methodology and Critical Mathematics Education. In: VALERO, Paola; ZEVEMBERGEN, Robyn. (Ed.). Researching the sócio-political dimension of Mathematics Education: issues of power in theory and methodology. New York: Kluwer Academic Publishers, 2004, p. 207-226.

SOUSA, Danielly Barbosa de; RÊGO, Rômulo Marinho do. 0 uso da Modelagem Matemática no estudo de Geometria no $8^{\circ}$ ano do Ensino Fundamental. In: XIII ENCONTRO BRASILEIRO DE ESTUDANTES DE PÓS-GRADUAÇÃO EM EDUCAÇÃO MATEMÁTICA, 2009, Goiânia. Anais do XIII EBRAPEM. Goiânia: UFG, 2009, p. 1-20. 